\title{
Normal Modes Analysis of Global Vibration pada Kapal Ikan Tradisional Tipe Purse Seine Daerah Batang
}

\author{
Hafez Ahmad Taury ${ }^{l)}$, Ahmad Fauzan Zakki ${ }^{1)}$ \\ ${ }^{1)}$ Departemen Teknik Perkapalan, Fakultas Teknik, Universitas Diponegoro \\ Jl. Prof. Soedarto, SH, Kampus Undip Tembalang, Semarang, Indonesia 5027
}

diajukan pada $: 27 / 05 / 18 \quad$ direvisi pada $: 01 / 06 / 18 \quad$ diterima pada $: 06 / 06 / 18$

\begin{abstract}
Abstrak
Getaran kapal dapat diklasifikasikan menjadi getaran global dan getaran lokal. Getaran global kerap kali terjadi pada kapal yang sedang beroperasi akibat adanya resonansi global. Resonansi global disebabkan oleh getaran eksitasi yang memiliki nilai frekuensi yang sama dengan frekuensi naturalnya. Resonansi global dapat menimbulkan terjadinya konsentrasi tegangan yang cukup signifikan pada bagian konstruksi. Selain itu, resonansi global juga dapat menyebabkan excessive deformation apabila terus diabaikan dalam waktu yang cukup lama. Artikel ini akan membahas getaran global pada kapal ikan tradisional tipe purse seine di daerah Batang, Jawa Tengah. Getaran global akan dianalisis menggunakan metode normal modes dalam software MSC. Nastran Patran. Dalam analisis ini akan mengasumsikan kapal bermuatan penuh dan bergetar bebas tanpa boundary condition. Hasil yang didapat dari analisis ini berupa frekuensi natural pada setiap mode getaran globalnya. Frekuensi natural yang dihasilkan antara lain 2,3481 Hz pada vertical vibration mode; 3,2081 Hz pada torsional vibration mode; dan 4,5596 Hz pada horizontal vibration mode. Setiap frekuensi natural yang dihasilkan akan dijumlahkan dengan frekuensi koreksi berdasarkan aturan Ship Vibration Control Guide 2000 guna dijadikan acuan dalam mencegah terjadinya resonansi global.
\end{abstract}

Copyright $@ 2018$, KAPAL, 1829-8370 (p), 2301-9069(e)

Kata Kunci : Getaran Global, Resonansi Global, Normal Modes, Frekuensi Natural, Mode Getaran Global.

\section{PENDAHULAN}

Getaran pada kapal dapat diklasifikasikan menjadi getaran global dan getaran lokal. Getaran global terjadi karena adanya resonansi global [1]. Resonansi global disebabkan oleh getaran eksitasi yang memiliki nilai frekuensi yang sama dengan frekuensi naturalnya [2]. Resonansi global dapat menimbulkan terjadinya konsentrasi tegangan yang cukup signifikan pada bagian konstruksi. Selain itu, resonansi global juga dapat menyebabkan excessive deformation apabila terus diabaikan dalam waktu yang cukup lama [1].

Penelitian mengenai getaran global telah banyak dilakukan pada kapal-kapal besar dibeberapa negara seperti China dan Turki. Hal ini dapat dibuktikan melalui artikel international [1]

*) Penulis Korespondensi :

Email : Hafezahmadtaury@gmail.com dan [3]. Penelitian ini menghasilkan nilai frekuensi natural dari kapal pada setiap mode getaran globalnya. Nilai frekuensi natural yang dihasilkan akan dijadikan acuan dalam mencegah terjadinya resonansi global.

Para pengrajin kapal kayu di daerah Batang, Jawa Tengah, terus melakukan pembangunan kapal guna memenuhi kebutuhan kapal tradisional di daerah tersebut. Namun, pertimbangan mengenai resonansi global masih belum dilakukan dalam proses pembangunannya. Oleh sebab itu, melalui artikel ini, penulis akan membahas tentang getaran global pada kapal ikan tradisional tipe purse seine daerah Batang, Jawa Tengah.

Tujuan dari pembahasan ini adalah untuk mencegah ataupun mengurangi terjadinya resonansi global pada kapal tersebut. Selain itu, pembahasan ini juga bertujuan untuk mengetahui 
apakah getaran main engine yang digunakan dapat menyebabkan terjadinya resonansi global pada kapal tersebut.

\section{METODE}

Getaran global akan dianalisis menggunakan metode normal modes dalam software MSC. Nastran Patran. Analisis ini akan mengasumsikan kapal bermuatan penuh dan bergetar bebas tanpa boundary condition. Analisis ini akan menghasilkan nilai frekuensi natural pada setiap mode getaran globalnya. Berdasarkan aturan Ship Vibration Control Guide 2000, untuk mencegah terjadinya resonansi global, nilai frekuensi eksitasi yang digunakan harus memiliki selisih sebesar $\pm 8 \%- \pm 10 \%, \quad \pm 10 \%- \pm 12 \%, \quad \pm 12 \%-$ $\pm 15 \%$ terhadap frekuensi naturalnya [5]. Oleh sebab itu, hasil dari analisis ini akan dijumlahkan dengan frekuensi koreksi berdasarkan nilai presentasi yang telah diatur dalam Ship Vibration Control Guide 2000 guna dijadikan acuan dalam mencegah terjadinya resonansi global.

\subsection{Pengumpulan Data}

Data yang dibutuhkan untuk proses analisis didapatkan melalui survey secara langsung dilapangan. Alat ukur yang digunakan antara lain meteran, tali, dan benda pemberat. Meteran digunakan untuk mengukur dimensi struktur konstruksi dan ukuran utama kapal. Tali dan benda pemberat digunakan sebagai alat bantu dalam mengukur bagian lengkung lambung kapal dan bagian vertikal seperti tinggi geladak utama kapal. Hasil pengumpulan data dapat dilihat pada Tabel 1.

Tabel 1. Hasil Pengumpulan Data

\begin{tabular}{cc}
\hline Parameter & Nilai \\
\hline LOA $(\mathrm{m})$ & 30 \\
LWL $(\mathrm{m})$ & 24 \\
$\mathrm{~B}(\mathrm{~m})$ & 8,2 \\
$\mathrm{~T}(\mathrm{~m})$ & 2,6 \\
H $(\mathrm{m})$ & 3,6 \\
Vs $($ knot $)$ & 15 \\
RPM Main Engine & 1800 \\
Displacement (ton) & 350 ton \\
\hline
\end{tabular}

\subsection{Pembuatan Lines Plan}

Kapal ikan tradisional di daerah Batang, Jawa Tengah, memiliki ciri khas model lambung dengan bentuk yang identik. Model tersebut dibangun tanpa didasari dengan desain lines plan melainkan didasari dengan keahlian dan kebiasaan secara turun temurun oleh para pengrajin kapal di daerah tersebut. Namun, desain lines plan merupakan salah satu data yang sangat dibutuhkan dalam proses analaisis ini. Oleh sebab itu, pembuatan desain lines plan akan dilakukan oleh penulis sebagai tahap awal dalam proses analisis ini.

Gambar 1 menunjukan desain lines plan dari kapal ikan tradisional daerah Batang, Jawa Tengah. Proses pembuatan ini dilakukan dengan menggunakan software AutoCAD $2 D$.

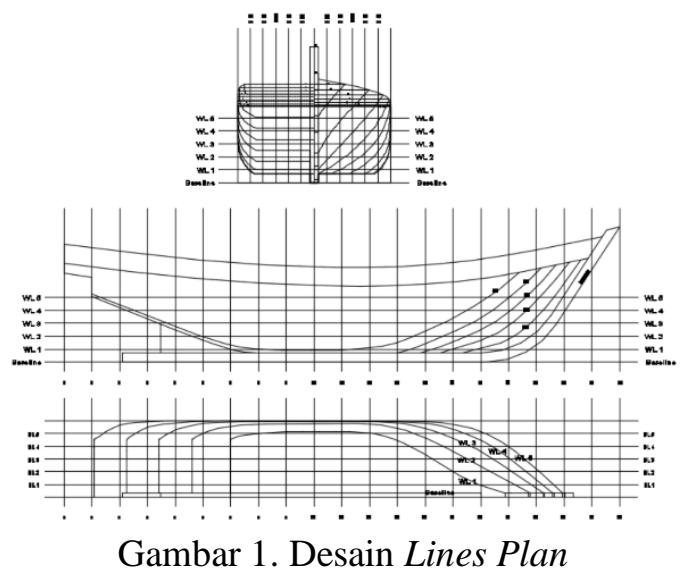

\subsection{Validasi Desain Lines Plan}

Tujuan dari validasi desain adalah untuk memastikan kebenaran dari koefisien design lines plan terhadap data objek yang diperoleh. Kebenaran tersebut dapat dipertimbangkan melalui data hydrostatic dan model 3D dari desain lines plan-nya.

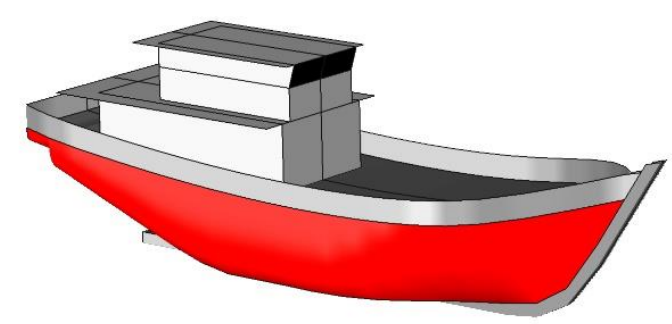

Gambar 2. Model 3D Kapal Ikan Tradisional

Tabel 2. Data Hydrostatic Model 3D

\begin{tabular}{cc}
\hline Parameter & Nilai \\
\hline $\mathrm{LWL}(\mathrm{m})$ & 23,946 meter \\
$\mathrm{B}(\mathrm{m})$ & 8,256 meter \\
$\mathrm{T}(\mathrm{m})$ & 2,6 meter \\
Displacement (ton) & 348,6 ton \\
$\mathrm{Cp}$ & 0,678 \\
$\mathrm{Cb}$ & 0,662 \\
$\mathrm{Cm}$ & 0,976 \\
$\mathrm{CWP}$ & 0,892 \\
\hline
\end{tabular}

Gambar 2 menunjukan model 3D dari kapal ikan yang akan di uji. Model 3D ini dibuat berdasarkan titik koordinat dari desain lines plan yang telah dibuat pada tahap sebelumnya. 
Software yang digunakan untuk membuat model ini adalah rhinoceros dan maxsurf modeller advance.

Tabel 2 menunjukan hasil perhitungan hydrostatic dari model 3D kapal ikan yang akan diuji. Berdasarkan hasil perhitungan hydrostaticnya, model 3D ini memiliki displacement sebesar 348,6 ton. Dengan demikian, displacement tersebut memiliki selisih nilai sebesar 1,4 ton atau sama dengan $0,4 \%$ terhadap terhadap data objek yang diperoleh (Tabel 1). Sehingga, dapat dikatakan bahwa koefisien dari model 3D yang digunakan telah menunjukan kesesuaian terhadap data objek yang diperoleh. Hal ini dikarenakan dengan menggunakan coefficient tersebut, model 3D ini menghasilkan displacement sebesar 348,6 ton dimana presentasi selisihnya masih dalam batas maksimum dari presentasi selisih yang diizinkan. Batas maksimum dari presentasi selisih displacement yang diizinkan adalah 5\% terhadap displacement yang direncanakan.

\subsection{Titik Gavitasi Model 3D}

Titik gravitasi kapal didapatkan melalui perhitungan berat dan titik berat setiap komponen LWT dan DWT [6]. Berat dan titik berat dari komponen LWT dihitung berdasarkan ukuran dimensi dan massa jenis kayu yang digunakan. Berat dan titik berat dari komponen DWT dihitung berdasarkan jenis muatan dan ukuran volume setiap kompartemen. Hasil perhitungan titik gravitasi kapal dapat dilihat pada tabel 3 dibawah ini.

Tabel 3. Titik Gravitasi Model 3D

\begin{tabular}{ccccc}
\hline Komponen & Berat (ton) & $\mathbf{X}(\mathbf{m})$ & $\mathbf{Y}(\mathbf{m})$ & $\mathbf{Z}(\mathbf{m})$ \\
\hline LWT & 112,7 & 11,84 & 0 & 3,751 \\
DWT & 237,356 & 16,461 & 0 & 2,034 \\
DISP & $\mathbf{3 5 0 , 0 5 6}$ & $\mathbf{1 4 , 9 7 3}$ & $\mathbf{0}$ & $\mathbf{2 , 5 8 7}$ \\
\hline
\end{tabular}

\subsection{Pembuatan Model Kapal Dalam Finine Element}

Model Finite Element dirancang berdasarkan model 3D dengan aturan Global Coordinate System dan satuan metric (ton, $\mathrm{m}, \mathrm{Hz}$ ). Aturan Global Coordinate System terdiri dari sumbu X, $\mathrm{Y}, \mathrm{Z}$ dengan susunan sebagai berikut :

- Koordinat $\mathrm{X}$ menunjukan arah memanjang kapal.

- Koordinat $\mathrm{Y}$ menunjukan arah melintang kapal.

- Koordinat $\mathrm{Z}$ menunjukan arah tinggi kapal.
Model finite element tersusun dari geometri surface dan curve yang telah didefinisikan menjadi sebuah elemen [7]. Geometri surface didefinisikan sebagai elemen kulit dengan tipe CQUAD4 dan CTRIA3 sedangkan geometri curve didefinisikan sebagai elemen beam dengan tipe bar2 [8]. Ukuran setiap elemen pada arah sumbu $\mathrm{X}, \mathrm{Y}$, dan $\mathrm{Z}$ dirancang dengan jarak 0.35 meter, 0.5 meter, dan 0.36 meter secara berturut - turut.

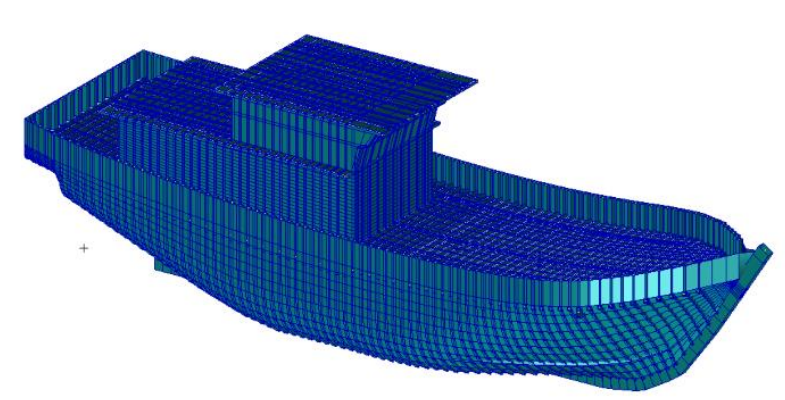

Gambar 3. Model Finite Element

\subsection{Propreties Material}

Elemen kulit dan beam pada model finite element didefinisikan sebagai material isotropic dengan properties kayu jenis bangkirai dan jati. Properties kayu jenis bangkirai dan jati didapatkan melalui refrensi [9]. Refrensi [9] digunakan untuk mengetahui kategori keawetan dan kekuatan berdasarkan jenis material kayunya serta untuk mengetahui nilai modulus young (E), poisson ratio, dan density berdasarkan katergori keawetan dan kekuatannya. Nilai properties material yang diperoleh dapat dilihat pada tabel 4 dan 5 dibawah ini.

Tabel 4. Properties Kayu Bangkirai

\begin{tabular}{cc}
\hline $\begin{array}{c}\text { Modulus Young (E) } \\
\text { Poisson Ratio } \\
\text { Density }\end{array}$ & $125 \times 10^{4} \mathrm{ton} / \mathrm{m}^{2}$ \\
\hline & 0,3 \\
Tabel 5 . Properties Kayu Jati $/ \mathrm{m}^{3}$ \\
\hline $\begin{array}{c}\text { Modulus Young (E) } \\
\text { Poisson Ratio }\end{array}$ & $100 \times 10^{4} \mathrm{ton} / \mathrm{m}^{2}$ \\
Density & 0,3 \\
\hline
\end{tabular}

Berat muatan dalam model finite element didefinisikan menggunakan element point mass pada setiap simpul di ruang muat, tanki bahan bakar, tanki minyak pelumas dan lain sebagainya. Perlu diketahui bahwa element point mass 
merupakan sebuah distribusi massa kecil tak berhingga dengan satuan ton per meter [10].

Proses input properties ke dalam model finite element akan menghasilkan informasi berupa nilai dan posisi dari titik gravitasi-nya. Nilai dan posisi dari titik gravitasi model finite element merupakan salah satu point penting untuk mendapatkan nilai frekuensi natural yang akurat.

Tabel 6 menunjukan nilai dan posisi titik gravitasi dari model finite element dan model 3D kapal ikan yang akan diuji. Pada tabel tersebut, dapat dilihat bahwa model finite element memiliki berat sebesar 350,1 ton sedangkan model 3D memiliki berat sebesar 350,056 ton. Perlu diketahui bahwa informasi nilai dan posisi titik gravitasi dari model 3D diperoleh melalui perhitungan LWT dan DWT yang telah dilakukan pada tahap sebelumnya (Tabel 3).

Tabel 6. Nilai dan Posisi Titik Gravitasi

\begin{tabular}{ccc}
\hline & Finite Element & Model 3D \\
\hline Berat & $350,1 \mathrm{ton}$ & $350,056 \mathrm{ton}$ \\
$\mathrm{X}$ & $14,43 \mathrm{~m}$ & $14,973 \mathrm{~m}$ \\
$\mathrm{Y}$ & $3,272 \times 10^{-11} \mathrm{~m}$ & $0 \mathrm{~m}$ \\
$\mathrm{Z}$ & $2,956 \mathrm{~m}$ & $2,587 \mathrm{~m}$ \\
\hline
\end{tabular}

\section{HASIL DAN PEMBAHASAN}

Normal mode analysis akan menghasilkan nilai frekuensi natural pada setiap mode getaran globalnya. Nilai frekuensi natural pada setiap mode getaran global yang dihasilkan dapat dilihat pada tabel 7 dan gambar 4 s.d. 6 dibawah ini.

Tabel 7. Frekuensi Natural

\begin{tabular}{cc}
\hline Mode Getar & Frekuensi Natural \\
\hline Vertical & $2,3481 \mathrm{~Hz}$ \\
Torsional & $3,2082 \mathrm{~Hz}$ \\
Horizontal & $4,5596 \mathrm{~Hz}$ \\
\hline
\end{tabular}

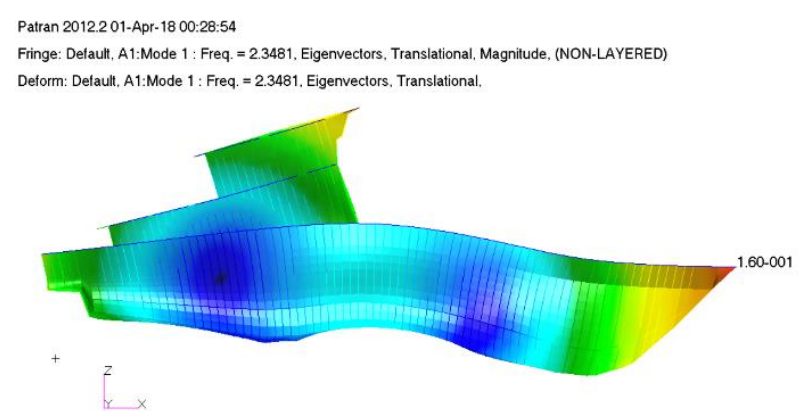

Gambar 4. Vertical Vibration Mode (2,3481 Hz)
Patran 2012.2 01-Apr-18 00:44:54

Fringe: Default, A1:Mode 2: Freq. $=3.2082$, Eigenvectors, Translational, Magnitude, (NON-LAYERED) Deform: Default, A1:Mode 2: Freq. $=3.2082$, Eigenvectors, Translational,

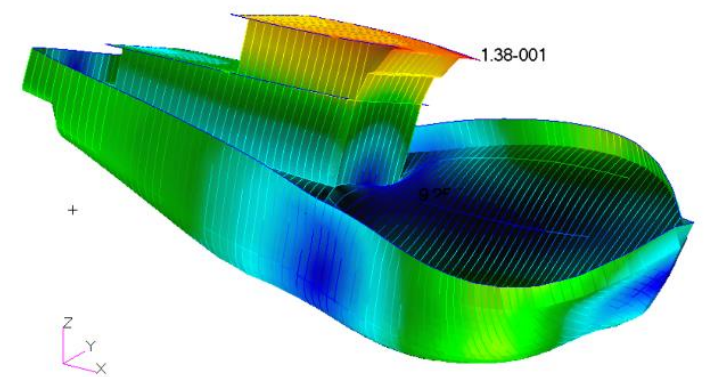

Gambar 5. Torsional Vibration Mode $(3,2082 \mathrm{~Hz})$

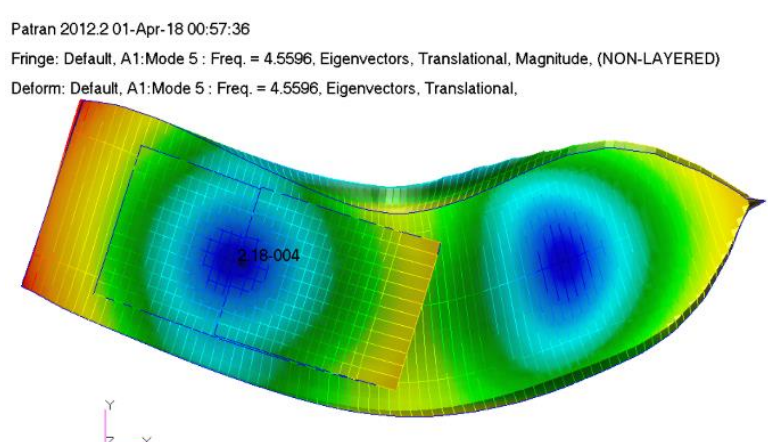

Gambar 6. Horizontal Vibration Mode $(4,5596 \mathrm{~Hz})$

Berdasarkan tabel 7 dan gambar 4 s.d. 6, dapat dilihat bahwa pada mode pertama, kapal ikan tradisional daerah batang jawa tengah akan mengalami vertical vibration mode pada frekuensi 2,3481 Hz. Pada mode kedua, kapal ini akan mengalami torsional vibration mode pada frekuensi 3,2082 Hz. Sedangkan pada mode ketiga, kapal ini akan mengalami horizontal vibration mode pada frekuensi 4,5596 Hz. Sehingga, dengan menggunakan aturan Ship Vibration Control Guide 2000, untuk mencegah terjadinya resonansi global baik secara vertical, torsional, maupun horizontal, kapal ini harus menghindari getaran eksitasi dengan frekuensi $2,11 \mathrm{~Hz}-2,58 \mathrm{~Hz} ; 2,82 \mathrm{~Hz}-3,59 \mathrm{~Hz}$; dan 3,88 $\mathrm{Hz}-5,24 \mathrm{~Hz}$.

\section{KESIMPULAN}

Diketahui bahwa kapal ikan tradisional daerah Batang, Jawa Tengah, menggunakan main engine dengan MCR 1800 RPM (30 Hz). Sehingga, dapat disimpulkan bahwa getaran main engine tidak akan menyebabkan terjadinya resonansi global baik secara vertical vibration mode, torsional vibration mode, maupun horizontal vibration mode. Hal ini dikarenakan resonansi global dengan tipe vertical vibration mode dapat terjadi pada frekuensi $2,11 \mathrm{~Hz}$ s.d. 2,58 Hz. Selain itu, resonansi global dengan tipe torsional vibration mode dan horizontal vibration 
mode juga dapat terjadi pada frekuensi $2,82 \mathrm{~Hz}$ s.d. $3,59 \mathrm{~Hz}$ dan $3,88 \mathrm{~Hz}$ s.d. 5,24 Hz.

\section{UCAPAN TERIMA KASIH}

Ucapan terima kasih penulis sampaikan kepada Bapak H. Nur Abadi selaku pemilik kapal ikan tradisional tipe purse seine daerah Batang, Jawa Tengah yang telah bersedia dan mengizinkan penulis untuk melakukan penelitian mengenai getaran global pada salah satu kapal yang beliau miliki. Selain itu, Penulis juga mengucapkan terima kasih kepada Bapak Dwi selaku general manager galangan kapal CV. Laksana Abadi yang telah membantu penulis dalam memperoleh data kapal yang dibutuhkan.

\section{DAFTAR PUSTAKA}

[1] F. Han, A. Hu, Y. Liu, and C. Wang, "Modelling and hull vibration calculation of very large container ship," vol. 18, no. 9, pp. 522-527, 2014.

[2] S. G. Kelly, "Mechanical Vibration: Theory and Aplication," S1 ed. Stamford: Cengage Learning, 2012.

[3] M. Engineer, M. Sc, and G. Manager, "Global Vibration Analysis of a 1900 Teu Capacitiy."

[4] Z. Arifin, A. F. Zakki, and M. Iqbal, "Studi Karakteristik Getaran Global Kapal Supply Vessel 70 m dengan Menggunakan Metode Elemen Hingga," 2017.

[5] American Bureau of Shipping (ABS), "ABS Guidance Notes On Ship Vibration", 2006.

[6] H. N. Wibowo, "KAJIAN NUMERIK RESPON GERAKAN KAPAL FPSOIFSO SAAT DITAMBAT (MOORED FPSOIFSO," 2012.

[7] Jurusan Teknik Kelautan FTK ITS, "Metode elemen hingga," 2010.

[8] A. F. Zakki, "Metode Elemen Hingga." UPT Undip Press Semarang, 2014.

[9] Anonim, "Peraturan Kapal Kayu Indonesia (PKKI)," Bandung, 1961.

[10] Joni Dewanto, "Kajian Teoritik Sistem Peredam Getaran Satu Derajat Kebebasan," J. Tek. Mesin, vol. 1, no. 2, pp. 156-162, 1999. 